N. ŻOŁEK*, Z. RANACHOWSKI*\#, P. RANACHOWSKI*, D. JÓŹWIAK-NIEDŹWIEDZKA*,

S. KUDELA JR.**, T. DVORAK**

\title{
STATISTICAL ASSESSMENT OF THE MICROSTRUCTURE OF BARITE AGGREGATE FROM DIFFERENT DEPOSITS USING X-RAY MICROTOMOGRAPHY AND OPTICAL MICROSCOPY
}

Two different barite ore (barium sulfate $\mathrm{BaSO}_{4}$ ) specimens from different localizations were tested and described in this paper. Analysis of the microstructure was performed on polished sections, and on thin sections using X-ray microtomography (micro-CT), and optical microscopy (MO). Microtomography allowed obtaining three-dimensional images of the barite aggregate specimens. In the tomograms, the spatial distribution of the other polluting phases, empty space as well as cracks, pores, and voids - that exceeded ten micrometers of diameter-were possible to visualize. Also, the micro-CT allowed distinguishing between minerals of different density, like $\mathrm{SiO}_{2}$ and $\mathrm{BaSO}_{4}$. Images obtained and analyzed on thin sections with various methods using the optical microscopy in transmitted light delivered additional information on the aggregate microstructure, i.e. allow for estimation of the different kinds of inclusions (like the different density of the minerals) in the investigated specimens. Above methods, which were used in the tests, completed each another in order to supply a set of information on inclusions' distribution and to present the important differences of the barite aggregate specimens microstructure.

Keywords: barite ore, barite aggregate, microstructure, optical microscopy, thin sections analysis, X-ray tomography

\section{Introduction}

Barite (barium sulfate $\mathrm{BaSO}_{4}$ ) and barite aggregates find widespread use in heavy industry, mining, Civil Engineering, and medicine as a chemically inert mineral with high specific gravity and increased shielding properties against gamma radiation. Barite ore is used as a weighting agent in drilling fluids (mud mix) [1]. Barite is also used as a pigment in paints [2] and as a weighted filler for paper, cloth and rubber [3]. Moreover, barite is the primary ore of barium, which is used to make a wide variety of barium compounds. Some of these and as an aggregate in a "heavy" cement were used for X-ray shielding [4].

It is known that when the content of heavyweight aggregates in concrete is increased, then concrete shields ensure attenuation of neutron flux and absorption of gamma radiation. Such concretes are used to built various kinds of shields in nuclear power plants and storages of radioactive waste. Commonly barite aggregate with mean density about $4,5 \mathrm{~g} / \mathrm{cm}^{3}$ is used to make high-density concrete to attenuate gamma ray emissions in power plants, laboratories, and hospitals. Influence of radiation on the concrete properties and microstructure made with different barite aggregate was presented in [5] and showed that barite aggregate should be carefully selected to design and perform heavy weight concrete for the purpose of shielding concrete. Barite aggregate varies depending on the deposit that is why a thorough analysis of its composition and the microstructure is desirable. Barite compounds were also used in diagnostic medical tests [2].

Barite is used in the fabrication of sintered hard-magnets [6]. Various pollutants contaminate barite deposits, what has a strong influence on the quality of resulting products of their processing.

The goal of the research was the microstructure analysis of different barite aggregate using complementary optical methods. The objective of this investigation was an application a different computer-aided microscopic and microphotography method of identification of the mineralogical composition and microstructure of high-density barite aggregates. In this work domestic and foreign barite, aggregate samples were analyzed - Figure 1.

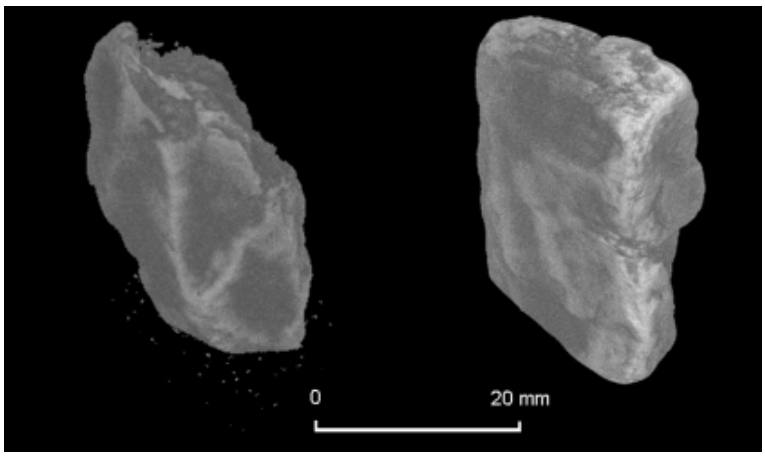

Fig. 1. Investigated barite aggregate samples from domestic (left) and foreign (right) deposits

\footnotetext{
* INSTITUTE OF FUNDAMENTAL TECHNOLOGICAL RESEARCH, POLISH ACADEMY OF SCIENCES, 5B PAWINSKIEGO STR., 02-106 WARSAW, POLAND

** INSTITUTE OF MATERIALS AND MACHINE MECHANICS, SLOVAK ACADEMY OF SCIENCES, DÚBRAVSKÁ CESTA 9, 845-13 BRATISLAVA, SLOVAK REPUBLIC 


\section{Testing methods-the microstructure analysis}

Analysis of the microstructure was performed using X-ray microtomography and optical microscopy on polished and thin sections.

The epoxy-impregnated thin sections were prepared from barite aggregate. The epoxy resin used for impregnation contained a fluorescent yellow dye. The barite grains were first impregnated and then cut into slices, and then vacuum impregnated. The aggregates were ground and polished to $20+2 \mu \mathrm{m}$ thickness thin sections. The section thickness was verified using the reference patterns for quartz color in the cross-polarized light. Thin section image acquisition was performed using an Olympus BX51 microscope in cross-polarized light (XPL) with $\lambda$ plate. The $\lambda$ plate is a first-order red plate which consists of a quartz or gypsum plate that is cut parallel to the optic axis, about $62 \mu \mathrm{m}$ thick, which shows a first-order red interference color in diagonal position [8].

Optical microscopy is applied to determine the microstructure of mineral specimens. It is also possible to improve images from optical microscope observations using a thin sections method and by adding a fluorescent feature, plane polarized and crossed polarized light techniques. The drawbacks of the optical microscopy include the limitation of the image resolution to single micrometers. It is caused by the relatively long wavelength of a visible light. Application of micro-CT method enables the use of more powerful sources of penetrating radiation with wavelengths shorter by two orders of magnitude. Then imaging of the entire specimen volume is possible. Micro-CT enables to obtain three-dimensional images (tomograms) of small barite aggregate samples specimens and allows the identification of inhomogeneities, sometimes impossible to visualize using 2D images obtained from only one direction. This is considered to be a remarkable improvement in comparison to the two-dimensional images, received using transmission optical microscopy. When the tomograms are subjected to processing - all other phase inclusions, cracks, pores and further voids, that exceed ca. ten micrometers, are possible to visualize. The authors have already applied the imaging procedures of micrographs and tomograms [7]. Statistical analyses of the distribution of inhomogeneities in the samples of barite aggregate extracted from the reconstructed 3D microstructure of specimens was performed and presented below.

\section{Analysis of the microscopic observations}

On the polished sections in optical microscopy, it was possible to recognize both large $(0.1-0.5)$ [mm] as well as small $(5-150)[\mu \mathrm{m}]$ inclusions. The inclusions in the foreign and in the domestic barite aggregate have different sizes. The size of the inclusions differs strongly, showing that the domestic aggregate includes larger contaminations than its foreign equivalent.

Figures 2-3 present the microscopic images of the polished sections of the barite aggregate originated from the foreign deposit. Typical structure-Figure 2-contains a small number of inclusions of the ovoid or elongated shape. Figure 3 depicts region where a number of the inclusions, especially bigger ones, is increased. The average diameter of typical inclusions falls in the range of $100 \div 150 \mu \mathrm{m}$. The small inclusions have a diameter of single to tens of micrometers. Comparing the barite aggregate originated from the foreign and domestic deposit one can mention that the latter barite has no uniform microstructure. The left side of Figure 4 presents the domestic specimen polished section where at least two different phases of various volume exist. The right side of Figure 4 illustrates the other case-the presence of increased number of the inclusions of different size and shape. The observations of the other domestic sample regions revealed that the big (ca. $0.5 \mathrm{~mm}$ ) inclusion diameter was greater than that found in the foreign samples and could even exceed $500 \mu \mathrm{m}$. However, there were observed areas which were homogeneous and contained an only small number of inclusions of varied shape and size-Figure 5.
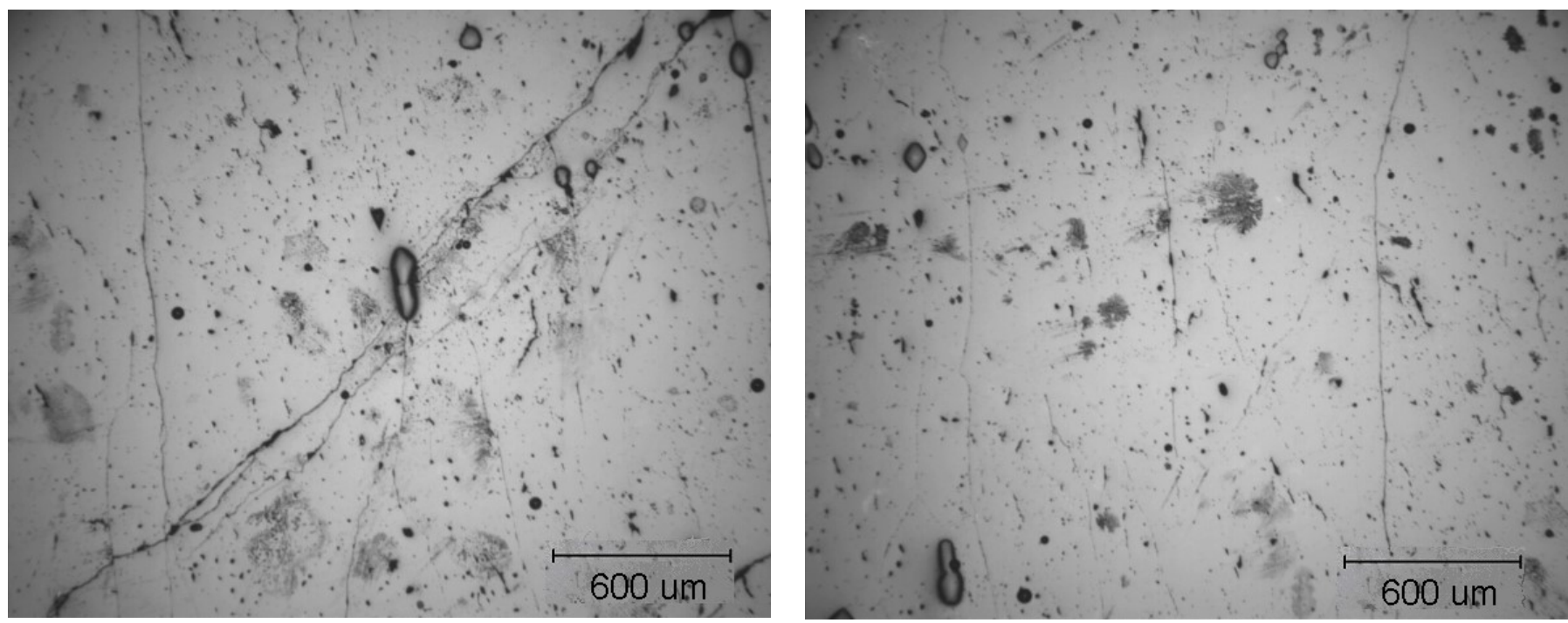

Fig. 2. Typical microscopic image of the foreign barite aggregate with small number of single inclusions, having a size in the range from tens to $250 \mu \mathrm{m}$. Inclusions have regular ovoid or elongated shape and do not form agglomerates (scale bar $=600 \mu \mathrm{m})$ 


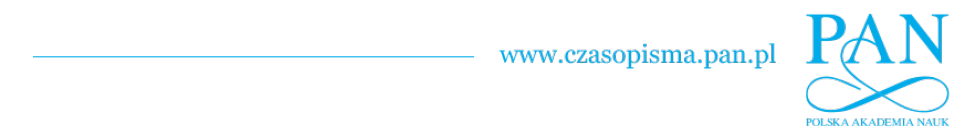

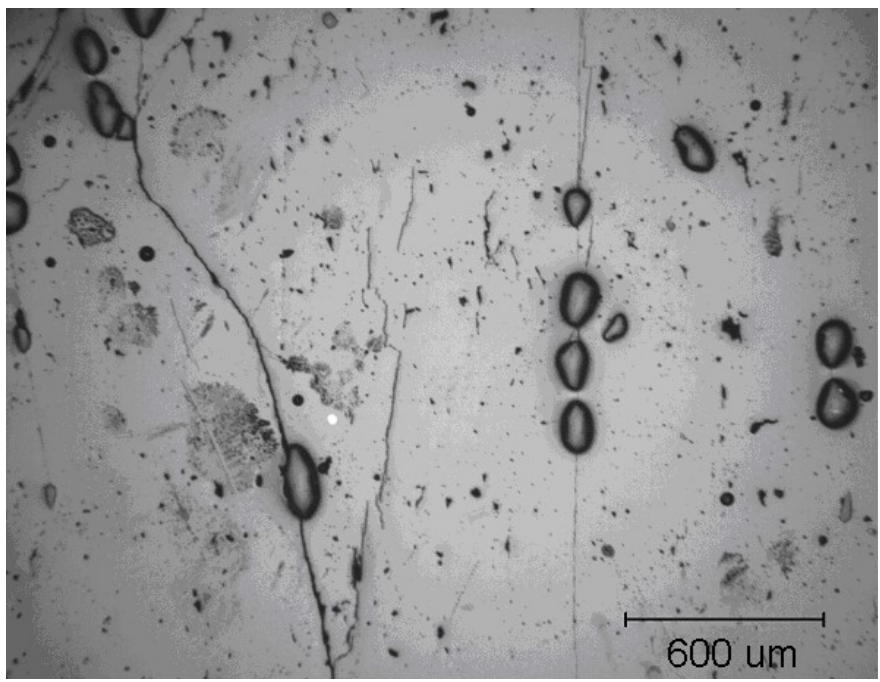

Fig. 3. Microscopic image of the region of the foreign barite sample with increased number of the inclusions. Their typical size is in the range of $100 \div 200 \mu \mathrm{m}$

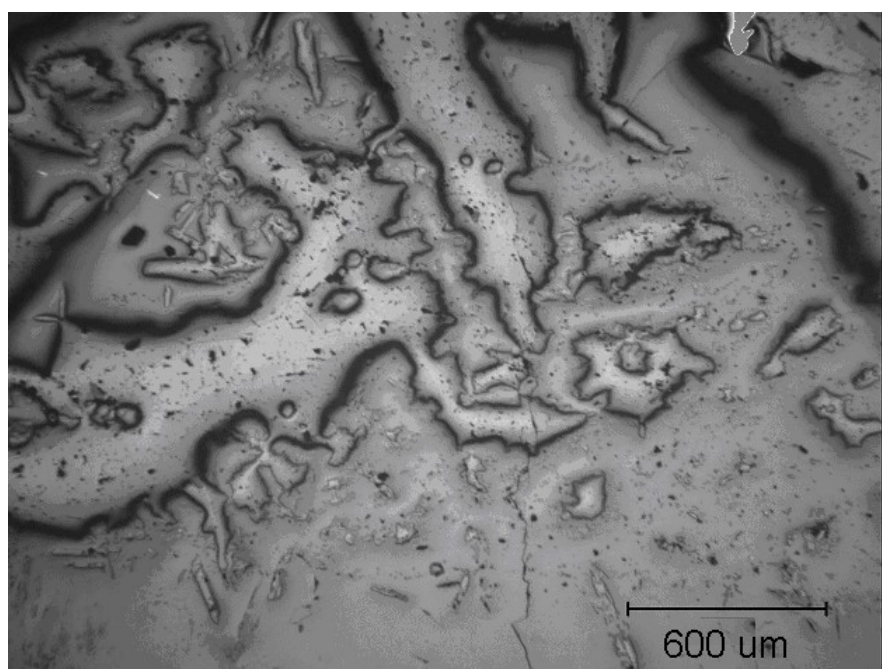

The micrographs presented in Figures $2 \div 5$ display the significant differences in inclusion content and size of the investigated barite aggregate. The differences denote the inclusion concentration, arrangement, their size, and shape.

Using transmitted polarized light microscopy on the thin sections it was possible to identify the inclusions in the barite aggregate as quartz particles. Smaller and larger quartz inclusions are visible more clearly in micrographs made in cross-polarized light with $\lambda$ plate. They are marked and shown in Figures 6 and 7. Number and size of the quartz particles are higher in the case of the domestic barite aggregate. As well as the range of their sizes seems to be much wider. In both samples inclusions are distributed unevenly. In Figure 6 an example of a single image $(1.5 \mathrm{~mm} \times 2 \mathrm{~mm})$ of the tested foreign aggregate is shown and in Figure 7-image of the whole aggregate grain on thin section is visible (for the domestic sample). The separate images were automatically acquired and assembled into one image, which was then subjected to a process of further analysis.

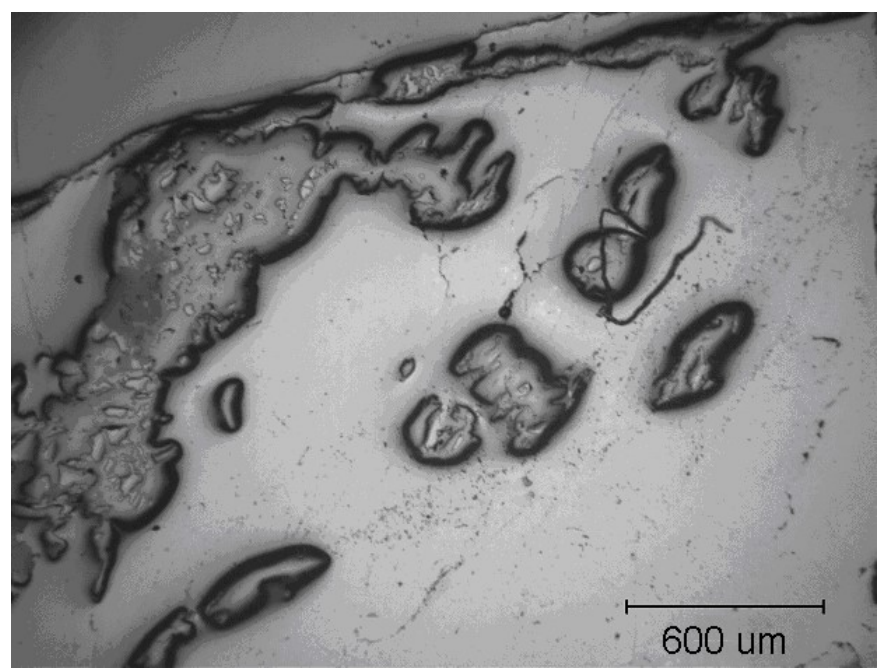

Fig. 4. (left): A vast multiphase area visible in the domestic barite aggregate. (right): The increased number of inclusions of different size and shape found in the same specimen

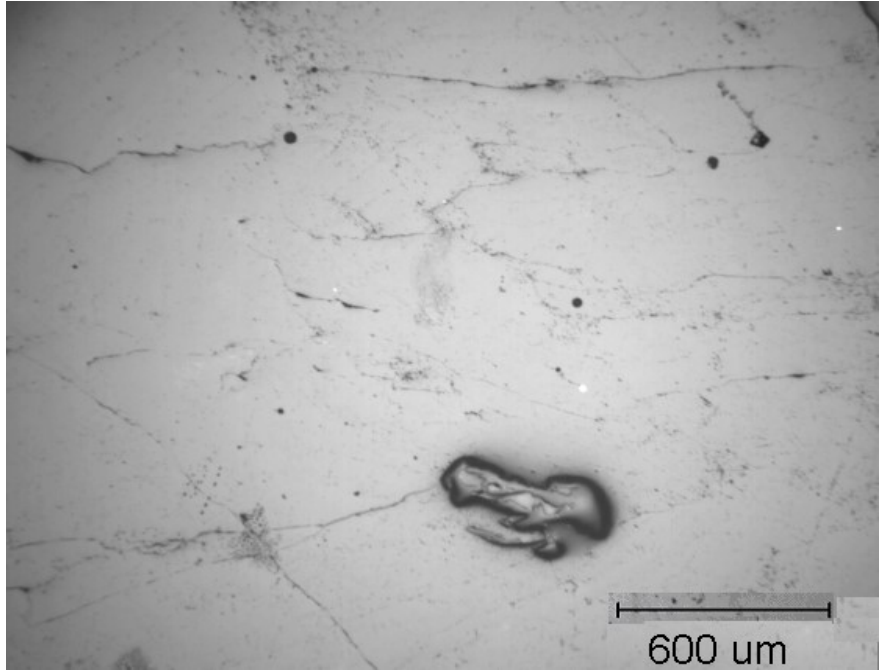

Fig. 5. Homogeneous area of the structure of the domestic barite aggregate. Only one big inclusion with a length of $540 \mu \mathrm{m}$ is visible (scale bar $=600 \mu \mathrm{m})$
The results of an investigation performed using crosspolarized light with $\lambda$ plate on the thin sections confirmed effects observed in the polished sections tests and enabled to identify the inclusions as the quartz particles.

\section{An aplication of micro-CT method}

Naked eye investigation of the barite aggregate grains showed the dark regions of discoloration over a bright specimen surface. However, in micro scale, it could be noticed that contamination inclusions have ovoid and/or elongated shape, possible to approximate by the ellipsoids. Their number, size, shape and distribution show large variations, especially when comparing aggregates from different deposits. Impurities could include several different substances, particularly in the case of the domestic ore. Typical contaminants include metal oxides - $\mathrm{CaO}, \mathrm{BaO}, \mathrm{PbO}$ and $\mathrm{SrO}$, clay minerals, silicate and sulfate 


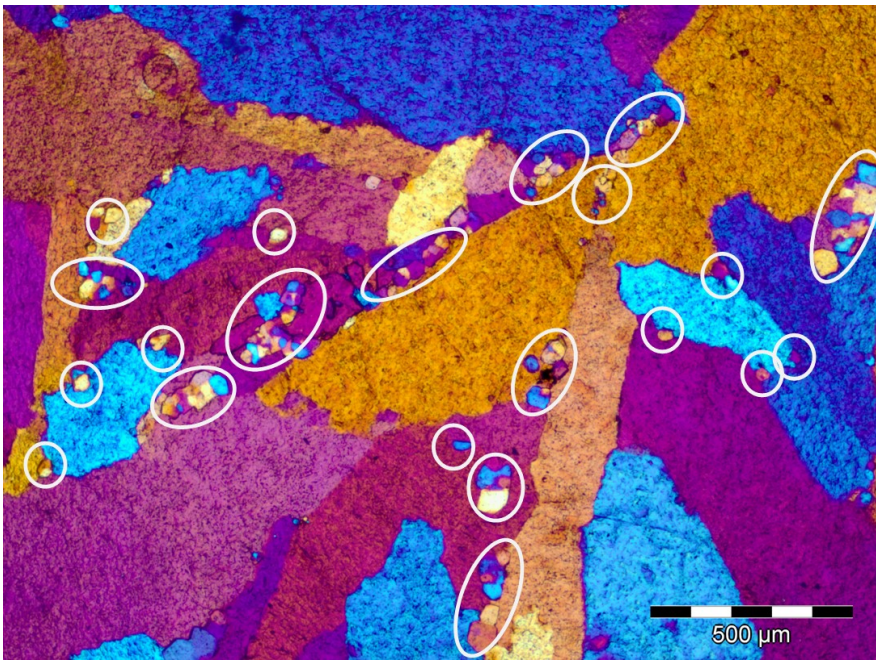

Fig. 6. Image of the foreign barite aggregate grain on thin section observed in XPL with $\lambda$ plate, visible quartz particles are marked (scale bar $=500 \mu \mathrm{m}$ )

minerals, possibly carbonates and fluorite $\left(\mathrm{CaF}_{2}\right)$. However, the most common constituent in a great number of the minerals is obviously quartz $\left(\mathrm{SiO}_{2}\right)$. Quartz can be considered, as one of the most common constituents of the barite aggregates, except to the largest and most desired content of the $\mathrm{BaSO}_{4}$

The 3D structures of the foreign and domestic barite aggregate specimens reconstructed on the basis of micro-CT data, are presented in Figure 8. Micro-CT method was applied using high-resolution Nanotom 30 microtomograph, operating in the Institute of Materials and Machine Mechanics SAS in Bratislava. The inclusions approximated by ellipsoids were contaminations by various pollutants, but mostly by quartz particles.

The digital data rely on the differences in density of the specimens content. By using the micro-CT scanning it was also

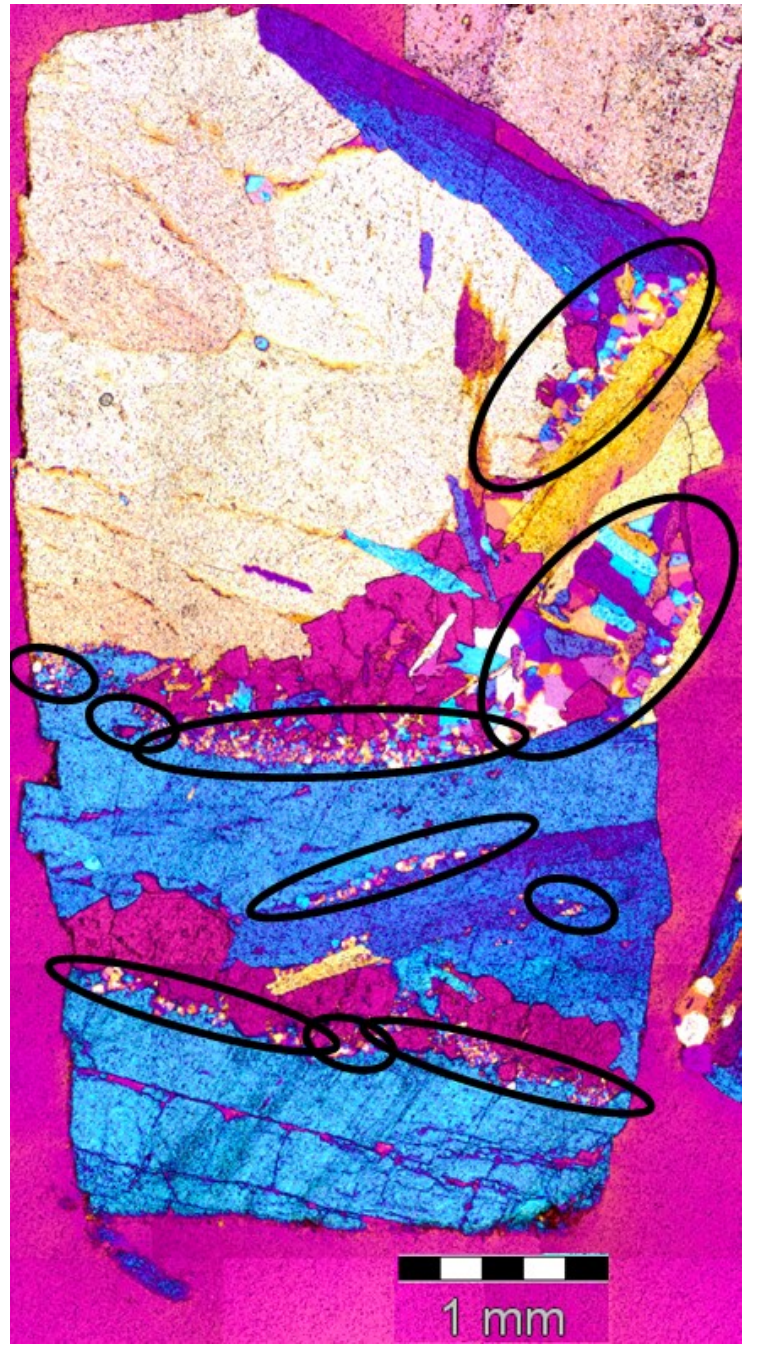

Fig. 7. Image of the domestic barite aggregate grain on thin section observed in XPL with $\lambda$ plate, visible quartz particles are marked (scale bar $=1 \mathrm{~mm}$ )
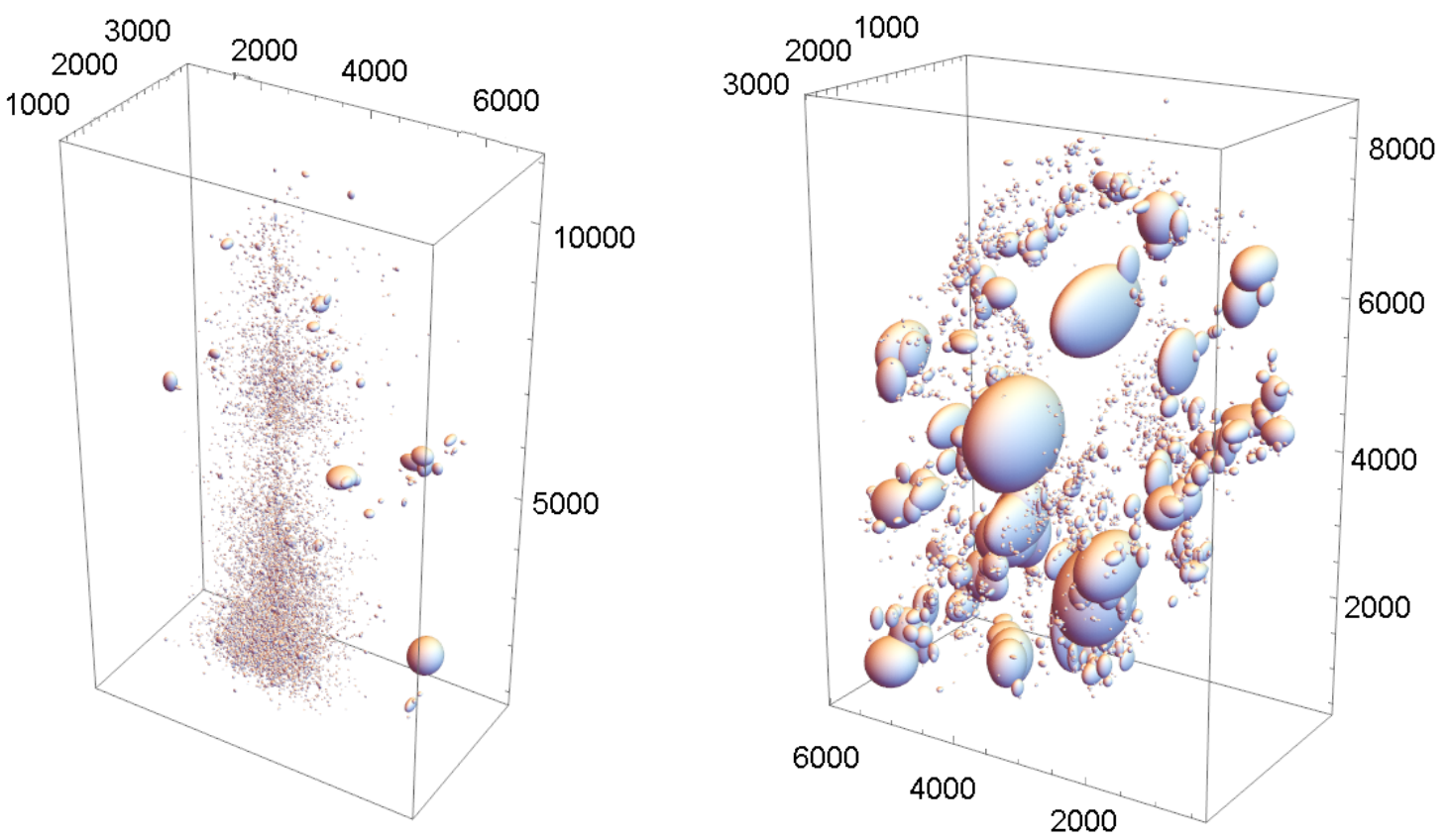

Fig. 8. The 3D visualizations of inclusions existing in the foreign (left) and domestic (right) barite aggregate specimens, reconstructed on the basis of micro-CT. Dimensions of the structures are presented in micrometer scale 
possible to present data in the form of the distributions of the inclusions' location and size. These distributions are presented in Figures $9 \div 11$. The distribution of the distance to the nearest neighbor inclusion is shown in Figure 9.

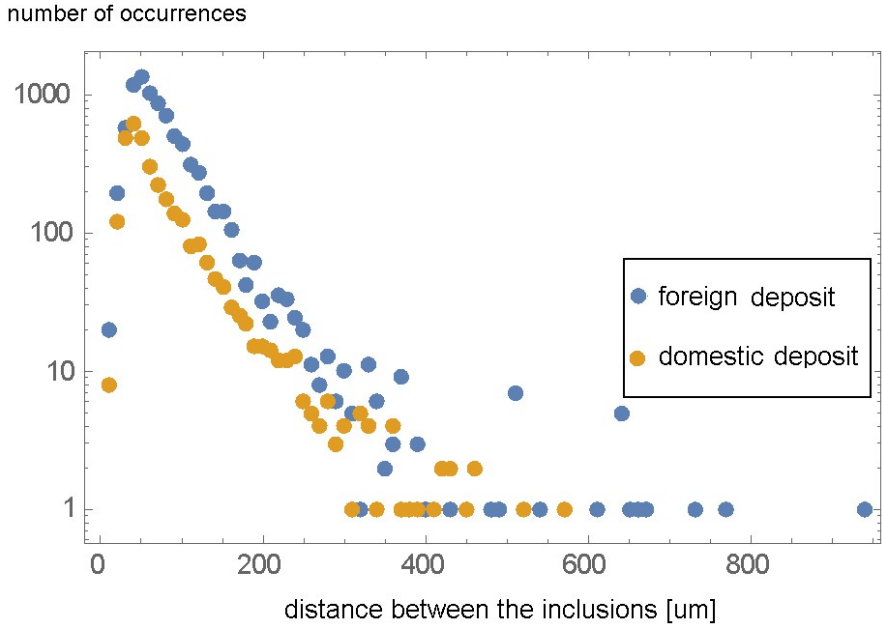

Fig. 9. Distribution of the nearest neighbor inclusions

Comparing the distributions presented in Figure 9 it can be noticed that the inclusions of all sizes in the foreign barite aggregate are spread throughout the specimen in more distant locations. In the domestic sample inclusions distribution density is considerably higher.

The data depicted in the inclusions size distributions, presented in Figure 10, confirm clearly that there are significantly more large inclusions in the domestic barite aggregate. It is also a much wider range of their sizes.

\section{number of occurrences}

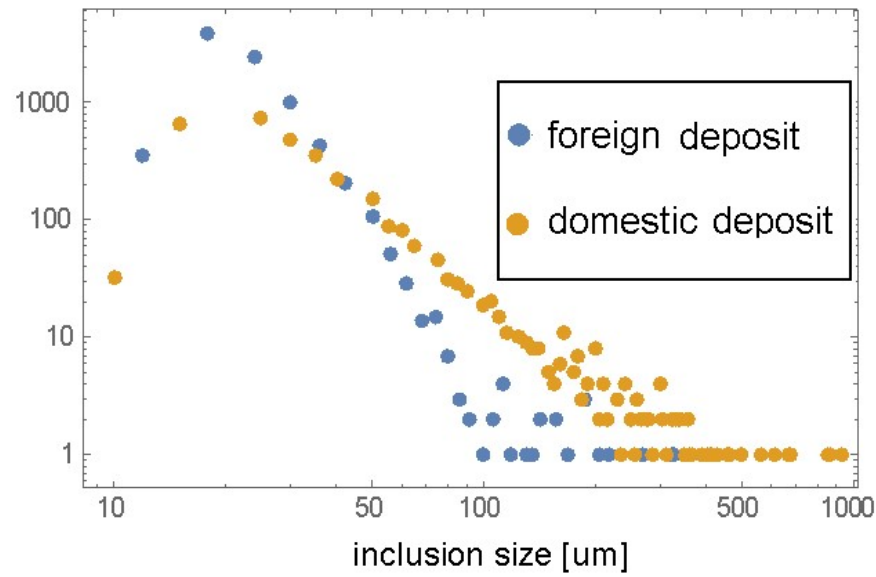

Fig. 10. Distribution of maximal dimension of ellipsoidal approximation of the inclusion particles

The other procedure involved in the micro-CT data presentation suit was the reconstruction of the inclusion particles volume, calculated in voxels expressed in cubic micrometers. The distribution of such inclusions' volume, approximated by ellipsoids, is presented in Figure 11. The general character of this parameter is similar as in Figure 10 and confirms significantly greater volume of the inclusion particles in the domestic barite aggregate as well as a much wider range of their sizes. These observations are consistent with the results of optical microscopy investigation of both barite specimens.

number of occurrences

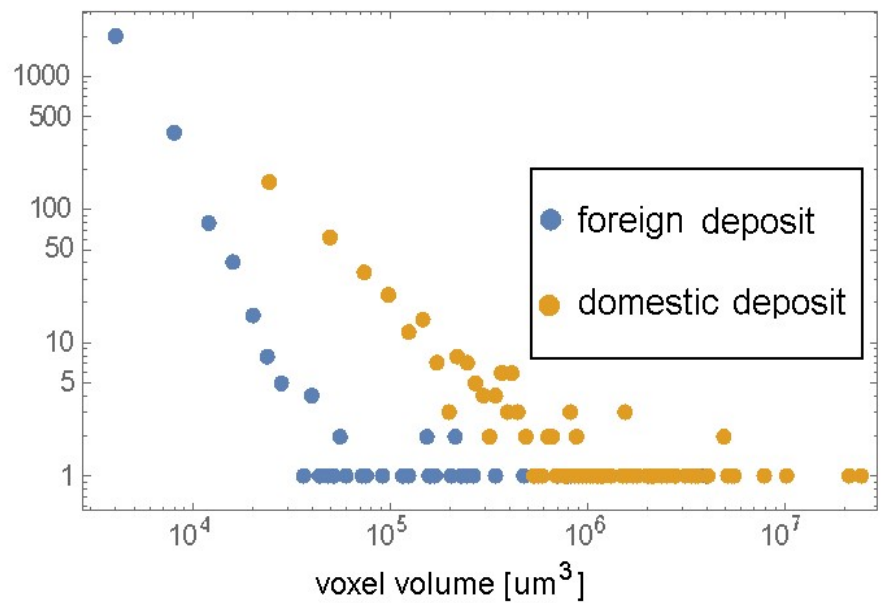

Fig. 11. Distribution of ellipsoidal approximation of the inclusion particles volume

\section{Conclusions}

The barite aggregate specimens originated from the foreign and domestic deposits generally differed between each other by mineralogical composition. The inclusions, most of all of quartz, observed in the foreign barite had the typical diameters in the range of $100 \div 150 \mu \mathrm{m}$ and occurred in significantly smaller number than those observed in the aggregate derived from the domestic deposit. The latter specimen had the inclusion diameter in the wide range. There were vast multiphase areas found too. The inclusion concentration was significantly higher in the case of the domestic sample. The inclusions were of different shapes and of several different mineralogical phases. However, the most important contaminant was quartz, what was revealed at micrographs made in polarized light. Different content of inclusions observed in two kinds of barite ores influences the way of their processing for further usage but both materials are in practice applicable in different kinds of the industry.

The goal of the work lays mostly in numerous micrographs depicting the microstructure of the investigated aggregate. Three different methods of investigation were applied in the research - optical microscopy on the polished section, analysis of the thin section in transmitted light, and most of all - 3D X-Ray microtomography (micro-CT).

The microtomography data allow to obtain an additional information concerning the detailed and proper statistical generalization of the barite aggregate results. Additionally, CT-method promote more detailed assessment of the specimen quality. It can be required in case of the use of barite aggregate in special applications, where the quality and the content of $\mathrm{BaSO}_{4}$ and $\mathrm{SiO}_{2}$ 
is of great importance. Further investigation of the additional barite aggregate from different deposits can give statistically more reliable results.

\section{REFERENCES}

[1] J.E. Kogel (Ed.), Industrial Minerals \& Rocks: Commodities, Markets, and Uses, 7th, Society for mining, metallurgy, and exploration, 2006, ISBN: 978-0873352499.

[2] I.A. Ibrahim, A.E. Mohamad, A.K. Ismail, in International Seminar on Mineral Processing Technology (MPT-2004), 2004, 285-292, http://www.min-eng.com/general/reps/28.html.
[3] P. Enghag, Encyclopedia of the Elements: Technical Data-History-Processing-Applications, Wiley \& Sons, Inc., 2004.

[4] A.T. Almeida, M.A.P. Dos Santos, M.S.N. Tavares, J.A. Filho, IFMBE Proc. 25, (3), 298-300 (2009).

[5] A.M. Brandt, D. Jóźwiak-Niedźwiedzka, Cement, Wapno, Beton 18, 4, 216-237 (2013)..

[6] M.M.S. Sanad and M.M. Rashad, Int. J. Miner. Metall. Mater. 23, (9), 991-1000 (2016).

[7] Z. Ranachowski, D. Józwiak-Niedźwiedzka, P. Ranachowski, F. Rejmund, M. Dąbrowski, S. Kudela, T. Dvorak, Arch. Metall. Mater. 59, (4), 1441-1447 (2014).

[8] D. Jóźwiak-Niedźwiedzka, R. Jaskulski, M.A. Glinicki, Materials, DOI: 10.3390/ma9040224, 9, 4 224-1-14 (2016). 